\title{
Exploring the Reaction Mechanism for Ozone Oxidation of Petrochemical Reverse Osmosis Concentrate by Resin Adsorption Chromatography
}

\author{
Weijun Tang ${ }^{1,2, a}$ \\ ${ }^{1}$ Beijing Metallurgical Equipment Research \& Design \\ Corporation Ltd. Of MCC Group, 100029, China \\ ${ }^{2}$ Technology Research Center of Beijing Steel and \\ Metallurgy Energy Saving Engineering, 100029, China \\ aemail: tangzhang8@yeah.net
}

\author{
Hua Zhang*,3, \\ ${ }^{3}$ CNPC Research Institute of Safety \& Environmental \\ Technology, \\ Beijing, 102206, China \\ bemail: zhanghua7977@163.com
}

\begin{abstract}
Dissolved organic matter (DOM) in petrochemical reverse osmosis concentrate (ROC) is important for developing ROC advanced oxidation techniques. In this studty, DOM before and after ozonation was fractionated using resin adsorbents into five classes: hydrophobic bases (HoB), hydrophobic acids (HoA), weakly hydrophobic acids (WHoA), hydrophobic neutrals (HoN) and hydrophilic matter (HiM). Hydrophobic organics dominate in DOM, in which HoN and HoA account for $29.2 \%$ and $19.5 \%$, respectively. Ozone significantly decreases the percentage of $\mathrm{HoN}$, while increases the concentration of WHoA and HiM. The UV-Vis analysis shows that ozonation decreases the molecular weight of DOM. In view of FTIR analysis, the unsaturated groups and aliphatic structurs are destroyed greatly and converted to more C-O structures, which shows relatively high hydrophilicity and low molecular weight. Through the analysis of fluorescence spectroscopy, it is found that ozone decreases significantly the fluorescence intensity of humic-like and fulvic-like substances in DOM, while increases the fluorescence intensity of soluble microbial products.
\end{abstract}

Keywords-reverse osmosis concentrate (ROC); ozone oxidation; DOM fractions

\section{INTRODUCTION}

Combined ultra-filtration (UF) and reverse osmosis (RO) membranes are widely used for direct reclamation of secondary sewage effluent from petrochemical enterprises.However, while RO membranes can remove efficiently most of organic and inorganic material, these rejected compounds are concentrated in the RO concentrate stream (ROC) [1]. ROC represents approximately 30 40\% of the inflow, depending on the RO recovery ratio and contains salts, dissolved organic matter (DOM) that were not removed in biological wastewater treatment. The direct discharge of the large amout of ROC is a serious waste of water resource and may have a negative impact on the aquatic ecosystem. As a consequence, further treatment of the concentrate could be necessary.

Presently, there is an increasing concern over the treatment of ROC. In general, treatment methods can be divided into two groups: high-energy oxidative methods (sonolysis, advanced oxidation, electrochemical oxidation), and those that consume chemicals (coagulation and adsorption). Several studies have shown that ozone treatment can be very efficient in the oxidation of a wide range of recalcitrant DOM [2-5]. In this study, ozonation is being investigated as a potential treatment option for ROC. However, studies about the reaction mechanism for ozonation of petrochemical ROC are still limited due to its complex composition of total DOM.

To understand the role of DOM in ozonation, it is often necessary to isolate DOM. Resin adsorption chromatography (RAC) is commonly used for isolating DOM from natural waters and has long been employed with a broad success [6]. Leenheer et al. [7] used resins to fractionate DOM of tertiary-treated municipal wastewater into hydrophobic acids, hydrophobic neutrals, hydrophilic acids, colloidal hydrophilic neutrals and dissolved hydrophilic neutrals. Imai et al. [8] modified the DOM fractionation method developed by Leenheer [9] and isolated DOM in effluents from sewage and human-wastes treatment plants into six classes: aquatic humic substances, hydrophobic neutrals and bases; hydrophilic acids, neutrals and bases. With the application of RAC, researchers have found out some characteristics of DOM from wastewater.

In this study, DOM in petrochemical ROC before and after ozonation was isolated into five classes using RAC technique. Combined with different analysis methods, the role of DOM characteristics was explored in ozonation of ROC. The results of this study will give us some fundamental ideas that which classes of DOM can be removed mostly in the ozonation of ROC.

\section{MATERIALS AND METHODS}

\section{A. Sample Collection and Preservation}

ROC samples were collected from a wastewater treatment plant in a petrochemical entrerprise. Water samples for this study were collected at RO site and filtered immediately through $0.45 \mu \mathrm{m}$ glass filter and stored in the dark at $4^{\circ} \mathrm{C}$ until analysis.

\section{B. Fractionation and Collection of DOM Fractions}

The fractionation of DOM was performed following the procedure modified from Imai et al. [8], Leenheer [9] and Chefetz et al. [10]. ROC was firstly pumped through a glass column of Sigma-Aldrich XAD-8 resin (20-60 mesh). Hydrophobic bases (HoB) were then desorbed from the resin with $0.1 \mathrm{M} \mathrm{HCl}$. The sample effluent was acidified to 
pH 2 with $6 \mathrm{M} \mathrm{HCl}$ and cycled over two connected Sigma-Aldrich XAD-8 and Sigma-Aldrich XAD-4 resin (60-80 mesh), respectively. The effluent from the connected two columns was hydrophilic matter (HiM). Hydrophobic acids (HoA) and weakly hydrophobic acids (WHoA) were desorbed from XAD-8 and XAD-4 with $0.1 \mathrm{M} \mathrm{NaOH}$, respectively. After HoA was desorbed, the XAD-8 resin was air-dried for about $12 \mathrm{~h}$ and was soxhlet-extracted with methanol to obtain hydrophobic neutrals $(\mathrm{HoN})$. The excess methanol was removed by vacuum-rotary evaporation at $40{ }^{\circ} \mathrm{C}$.

\section{Organic Carbon Analysis}

Dissolved organic carbon (DOC) was measured with a TOC analyzer (Multi N/C 3000) in accordance with Standard Method 5310D. The UV254 to DOC ratio (SUVA) was reported to represent the aromatic characteristic of organic matters as they imparted the ability to absorb light in the UV range [11].

\section{Fourier Transform Infrared Spectroscopy (FTIR) Analysis}

DOM powder obtained through freeze-drying the fractions was analyzed for the structural and chemical characteristics of DOM. $\mathrm{KBr}$ was mixed with the DOM powder about the ratio of 100 to 1 and the FTIR spectra of the mixture were obtained by scanning it with FTIR spectrometer (Thermo Nicolet 5700, USA).

\section{E. Fluorescence Spectroscopy Analysis}

Fluorescence spectra were recorded on a fluorescence spectrophotometer (model F-4500, Hitachi, Japan). Three-dimensional spectra were obtained by measuring the emission spectra in the range from 250 to $550 \mathrm{~nm}$ repeatedly, and at the excitation wavelengths from 230 to $420 \mathrm{~nm}$, at $5 \mathrm{~nm}$ intervals in the excitation domain.

\section{RESULTS AND DISCUSSION}

\section{A. Water Quality of ROC}

Raw ROC samples were collected periodically at the RO site of petrochemical wastewater. As shown in table I, its SUVA is $1.65 \mathrm{~L} /(\mathrm{cm} \cdot \mathrm{g})$ comparable with that of municiple wastewater [12]. Dissolved COD is about $95 \%$ of total COD, indicating that DOM is the main organics in ROC. The BOD/COD ratio is 0.24 below 0.30 , showing that DOM is not so biodegradable which suggests that advanced oxidation such as ozonation may be a better pretreatment method.

TABLE I. WATER QUALITY OF ROC

\begin{tabular}{|c|c|c|c|c|c|c|c|c|}
\hline $\mathrm{pH}$ & total alkalinity & $\begin{array}{c}\text { Conductivity } \\
(\mathrm{ms} / \mathrm{cm})\end{array}$ & $\begin{array}{c}\mathrm{NH}_{3}-\mathrm{N} \\
(\mathrm{mg} / \mathrm{L})\end{array}$ & $\begin{array}{c}\text { DOC } \\
(\mathrm{mg} / \mathrm{L})\end{array}$ & $\begin{array}{c}\mathrm{COD} \\
(\mathrm{mg} / \mathrm{L})\end{array}$ & Dissolved COD(mg/L) & $\begin{array}{c}\text { BOD } \\
(\mathrm{mg} / \mathrm{L})\end{array}$ & $\begin{array}{c}\text { SUVA } \\
\mathrm{L} /(\mathrm{cm} \cdot \mathrm{g})\end{array}$ \\
\hline $4.51 \pm 0.1$ & $12.02 \pm 0.05$ & $12.31 \pm 0.05$ & 0.9 & $56.4 \pm 0.5$ & $350 \pm 10$ & $330 \pm 10$ & $88.68 \pm 11$ & $1.65 \pm 0.05$ \\
\hline
\end{tabular}

\section{B. Ozonation of ROC}

Ozone was continuously introduced into $1 \mathrm{~L}$ raw ROC at a constant flow of $1.8 \mathrm{mg} / \mathrm{min}$ for $30 \mathrm{~min}$. Ultraviolet spectrophotometry, FTIR and fluorescence spectroscopy were employed to characterize DOM before and after ozonation.

1) UV-Vis analysis

The spectrophotometric scanning spectra $(220-400 \mathrm{~nm})$ of ROC before and after ozonation are shown in Fig.1 (a). Due to the existence of a variety of functional groups, there is no obvious characteristic peak among the scanning UV-visible region. It is observed that ROC after ozonation shows a significant decrease in absorbance among the range of $230-400 \mathrm{~nm}$ compared to $\mathrm{ROC}$, indicating that $\mathrm{O}_{3}$ sharply removed or varied the fractions with absorbance wavelength above $230 \mathrm{~nm}$. Schnitzer et al. [13] suggested that aramatic $\mathrm{C}=\mathrm{C}$, ketone carbonyl $\mathrm{C}=\mathrm{O}$, and some auxochrome groups (such as $\mathrm{C}-\mathrm{OH}$ and $-\mathrm{NH}_{2}$ ) showed obvious absorbance in 254-280 nm UV region.

$\mathrm{UV}_{254}$ (absorbance of $\mathrm{UV}$ at $254 \mathrm{~nm}$ ) to DOC ratio, i.e. $\mathrm{SUVA}_{254}$, is commonly reported to represent the aromatic character of organic matters as they imparted the ability to absorb light in the UV range [11]. $\mathrm{UV}_{250} / \mathrm{UV}_{365}$ is also employed to represent the aromaticity and molecular weight of DOM. It is reported that lower $\mathrm{UV}_{250} / \mathrm{UV}_{365}$ exhibits higher molecular weight [14]. Figure 1 (b) shows the variation of specific UV absorbances during ROC ozonation for $30 \mathrm{~min}$. It is observed that $\mathrm{SUVA}_{254}$ decreases sinificantly during the initial $20 \mathrm{~min}$, while varies gently in the final $10 \mathrm{~min}$. On the contrary, $\mathrm{UV}_{250} / \mathrm{UV}_{365}$ increases sharply during the initial $20 \mathrm{~min}$ and keep increasing slowly in the following $10 \mathrm{~min}$. It can be concluded that some functional groups especially unsaturated bonds in ROC are subjected to $\mathrm{O}_{3}$ attack in the initial $20 \mathrm{~min}$, which results in the lower molecular weights and lower aromaticity. 

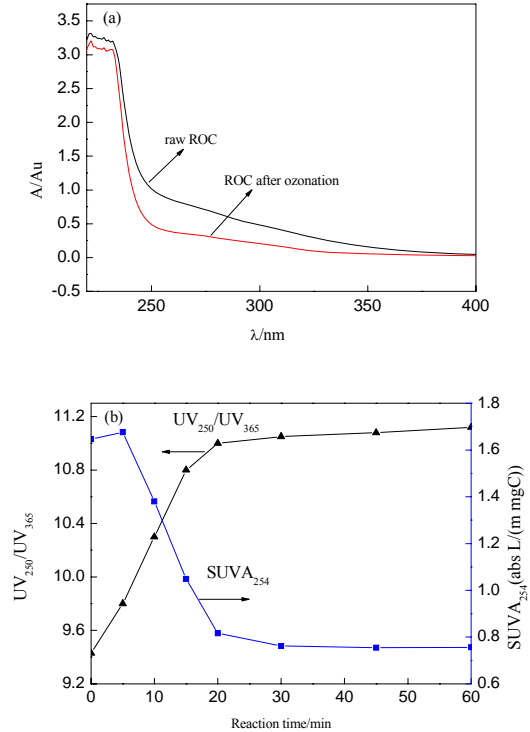

Figure 1. (a) Spectrophotometric scanning spectra of ROC before and after ozonation and (b) UV absorbance ratios at different wavelengths.

\section{2) FTIR}

The FTIR spectra of ROC before and after ozonation are shown in Figure 2. Interpretation of the absorption bands of DOM was done as described in the literature [7, 15-17].

ROC before and after ozonation are similar in spectra with three distinctive adsorption bands: $1600-1650 \mathrm{~cm}^{-1}$ suggesting aromatic skel $\nu \mathrm{C}=\mathrm{C}$ or aldehydate and ketonate groups $\vee \mathrm{C}=\mathrm{O} ; 1380-1400 \mathrm{~cm}^{-1}$ attributed to aliphatic structures containing $\mathrm{C}-\mathrm{H}$ functional groups; and 900-1200 $\mathrm{cm}^{-1}$ largely due to carbohydrates $\mathrm{vC}-\mathrm{C}$ or $\mathrm{O}$-alky group $v(\mathrm{C}-\mathrm{O})$. It is observed that compared to raw ROC, the DOM after ozonation exhibited a relatively weak peak at $1631 \mathrm{~cm}^{-1}$ which is defined as the aromatic structures, whereas the adsorption peak around $1380-1400 \mathrm{~cm}^{-1}$ is obviously enhanced. The results indicate that the aramatic and long chain structures of ROC are destroyed under the attack of $\mathrm{O}_{3}$ leading to the decrease in aromaticity and molecular weights, which is consistent with the conclusion of UV-Vis analysis.

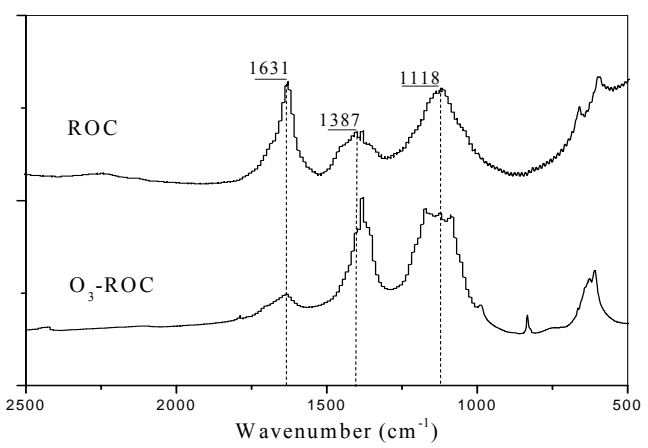

Figure 2. FTIR spectra of ROC before and after ozonation

\section{3) $3 D-E E M$}

Excitation emission matrix (EEM) was used to characterize ROC before and after ozonation. The contour maps of the results showed that ROC contains similar peaks with quite different fluorescence intensity (Figure 3). The substances and fluorescence intensity corresponding to the peaks are shown in Table II.


Figure 3. 3D-EEM spectrums of ROC before and after ozonation

TABLE II. EEM PEAKS FOR THE DOM FRACTIONS.

\begin{tabular}{|c|c|c|c|}
\hline & $\begin{array}{l}\mathrm{Ex} / \mathrm{Em} \\
(\mathrm{nm} / \mathrm{nm})\end{array}$ & Fluorescence substances & $\begin{array}{l}\text { Intensity } \\
\text { (on a per carbon basis) }\end{array}$ \\
\hline \multirow{2}{*}{ raw $\mathrm{ROC}$} & $330 / 400$ & humic-acid like products & 25.96 \\
\hline & $250 / 400$ & fulvic-acid like products & 7.75 \\
\hline \multirow[t]{3}{*}{ ROC after ozonation } & $330 / 410$ & humic-acid like products & 2.70 \\
\hline & $260 / 418$ & fulvic-acid like products & 1.45 \\
\hline & $280 / 320$ & Soluble microbial products & 1.69 \\
\hline
\end{tabular}


Humic and fulvic acids are the main fluorescence substances in raw ROC, indicating a large amount of unsaturated aromatic structures. After ozonation, the intensity of humic and fulvic acids is greatly decreased and a new peak standing for soluble microbial products appears. The results are consistent with the above analysis. $\mathrm{O}_{3}$ oxidizes and destroys the aromatic groups such as humic and fulvic acid-like products and accordingly results in the production of soluble microbial products to some extent, which are attributed to the increase of biodegradability.

\section{Fractionation of ROC before and after Ozonation}

\section{1) DOC distribution and SUVA of DOM fractions}

Ozone was continuously introduced into DOM for 30 min and resins were used to fractionate ROC before and after ozonation. The SUVA and DOC percentage of ROC fractions before and after ozonation are presented in Figure 4.

It is found that after ozonation, the DOC percentage of hydrophobic organics in raw ROC drops from 52.4\% to $39.7 \%$, in which a substantial decrease from $29.1 \%$ to $14.4 \%$ in the percentage of $\mathrm{HoN}$ is observed. Correspondingly, the DOC percentage of WHoA increases from $16.7 \%$ to $23.9 \%$ and HiM increases from $30.9 \%$ to $36.4 \%$. On the other hand, 30 min ozonation results in a decrease of DOC by $18.3 \%$, which suggests that ozonation results in a little mineralization, yet alters the structures of ROC to more hydrophilic.

The SUVA of raw ROC fractions is at 0.71-1.88 $\mathrm{L} /(\mathrm{mg} \cdot \mathrm{m})$, especially HoA showing the highest of 1.88 $\mathrm{L} /(\mathrm{mg} \cdot \mathrm{m})$. A significant decrease in SUVA of ROC fractions is observed after ozonation, suggesting the obvious change of aromatic structures. In particular, the SUVA of WhoA decreases from $1.78 \mathrm{~L} /(\mathrm{mg} \cdot \mathrm{m})$ to $0.60 \mathrm{~L} /(\mathrm{mg} \cdot \mathrm{m})$, while hydrophobic organics such as HoA and HoN still exhibit relatively high SUVA, $1.09 \mathrm{~L} /(\mathrm{mg} \cdot \mathrm{m})$ and $1.11 \mathrm{~L} /(\mathrm{mg} \cdot \mathrm{m})$, respectively.
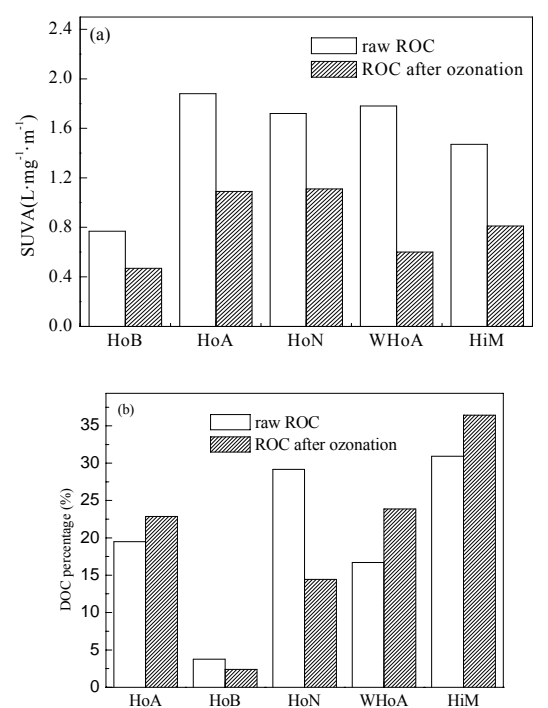

Figure 4. Distribution and SUVA of DOM fractions in ROC before and after ozonation. (a) SUVA and (b) DOC percentage.

\section{2) FTIR Analysis of DOM Fractions}
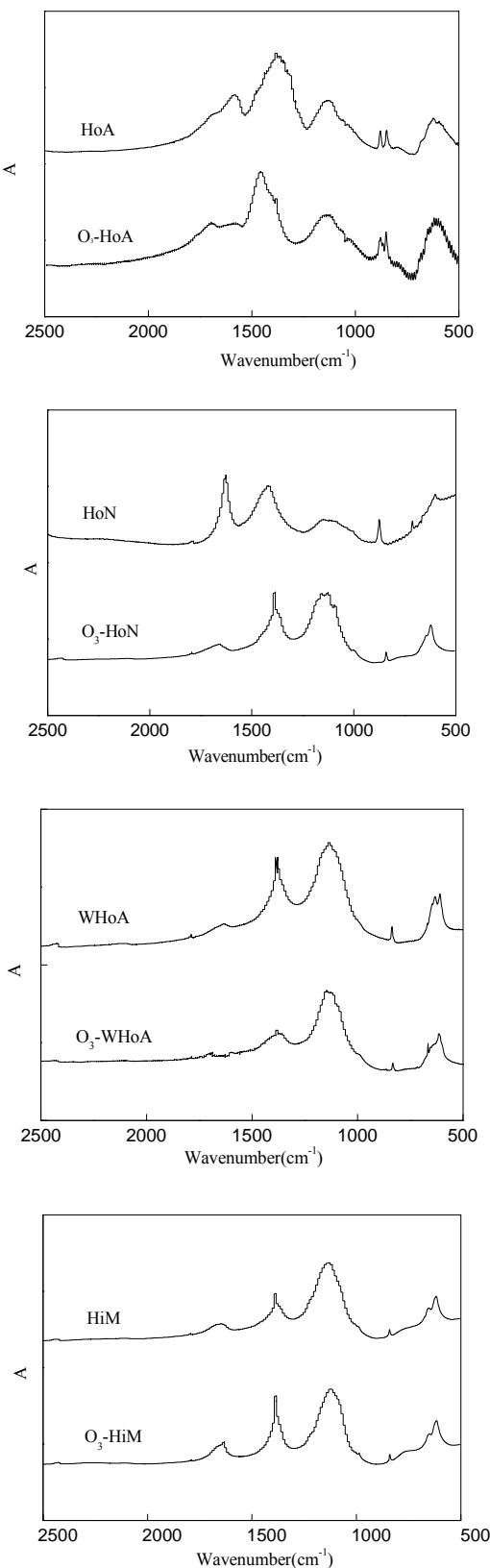

Figure 5 .The FTIR spectrums of DOM fractions before and after ozonation. DOM fractions of raw ROC are HoA, HoN, WhoA and HiM. DOM fractions of ROC after ozonation are O3-HoA, O3-HoN, O3-WhoA and $\mathrm{O} 3-\mathrm{HiM}$.

Figure 5 shows the FTIR analysis of ROC fractions before and after ozonation. It is observed that there is a similar peak around $1600-1650 \mathrm{~cm}-1$ for the four main fractions of ROC which is defined as the aromatic structures containing $\mathrm{C}=\mathrm{C}$ bonds. Compared to WHoA and HiM, the hydrophobic fractions exhibit a relatively strong peak around 1600-1650 cm-1 suggesting relatively high aromaticity. After ozonation, the peaks around 1600-1650 
cm-1 of the hydrophobic fractions are significantly weakened, in particular $\mathrm{HoN}$, whereas the peak around 900-1200 cm-1 due to hydroxy acids or O-alky group $\mathrm{v}(\mathrm{C}-\mathrm{O})$ for $\mathrm{HoN}$ is greatly enhanced. It is believed that the decrease in aromatic structures and increase in $\mathrm{v}(\mathrm{C}-\mathrm{O})$ groups cause ROC to be more hydrophilic after ozonation.

3) 3D-EEM Analysis of DOM Fractions

Figure 6 shows the 3D-EEM spectra of ROC fractions before and after ozonation. The contour maps of the results show that different fractions exhibited different peaks and ozonation significantly decrease the fluorescence intensity. Table 3 exhibits the substances and fluorescence intensity corresponding to the peaks.
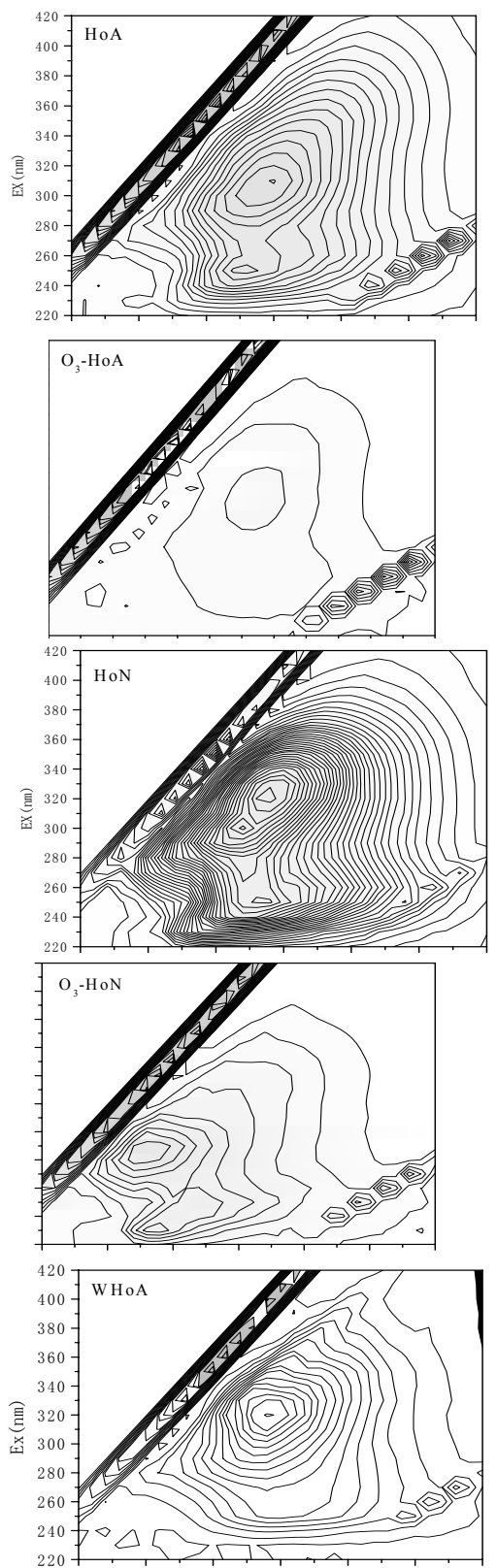
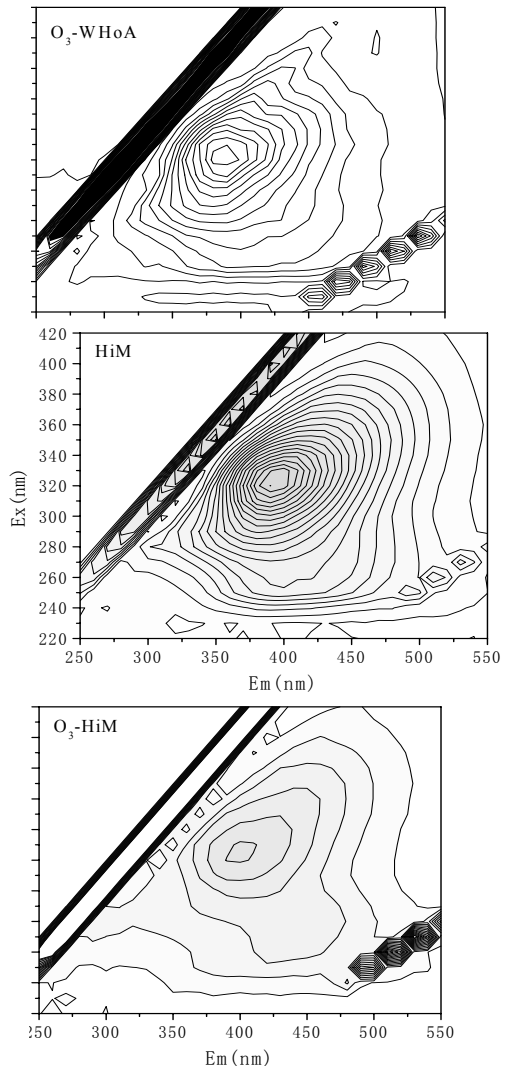

Figure 6. The 3D-EEM spectrum of the DOM main fraction before and after ozonation. DOM fractions of raw ROC are HoA, HoN, WhoA and HiM. DOM fractions of ROC after ozonation are O3-HoA, O3-HoN, $\mathrm{O} 3-\mathrm{WhoA}$ and $\mathrm{O} 3-\mathrm{HiM}$.

As shown in table III, humic-acid and fulvic-acid like products are main fluorescence substances in raw ROC fractions. After ozonation, the intensity of the main fluorescence substance is decreased, especially HoA, HoN and WhoA. Moreover, soluble microbial products appear in HoA, HoN and HiM after ozonation. In particular, HiM after ozonation exhibits the highest intensity of soluble microbial products on a per carbon basis.

In consideration of the above analysis, it can be concluded that the production of soluble microbial products cause ROC to be more hydrophilic, which contains more O-alky v $(\mathrm{C}-\mathrm{O})$ groups. 
TABLE III. FLUORESCENCE PEAK AND INTENSITY OF DOM MAIN FRACTION BEFORE AND AFTER OZONATION

\begin{tabular}{|c|c|c|c|c|c|c|}
\hline & \multicolumn{3}{|c|}{ raw $\mathrm{ROC}$} & \multicolumn{3}{|c|}{ ROC after ozonation } \\
\hline & $\begin{array}{c}\mathrm{Ex} / \mathrm{Em} \\
(\mathrm{nm} / \mathrm{nm})\end{array}$ & Fluorescence substances & $\begin{array}{c}\text { Intensity } \\
\text { (on a per carbon basis) }\end{array}$ & $\begin{array}{c}\mathrm{Ex} / \mathrm{Em} \\
(\mathrm{nm} / \mathrm{nm})\end{array}$ & Fluorescence substances & $\begin{array}{c}\text { Intensity } \\
\text { (on a per carbon basis) }\end{array}$ \\
\hline \multirow[t]{2}{*}{ HoA } & $400 / 390$ & humic-acid like products & 54 & $400 / 390$ & humic-acid like products & 42 \\
\hline & $250 / 380$ & fulvic-acid like products & 24 & $295 / 295$ & Soluble microbial products & 66 \\
\hline \multirow[t]{3}{*}{$\mathrm{HoN}$} & $325 / 390$ & humic-acid like products & 71 & $395 / 390$ & humic-acid like products & 62 \\
\hline & $250 / 390$ & fulvic-acid like products & 38 & $285 / 300$ & fulvic-acid like products & 37 \\
\hline & & & & $230 / 340$ & Soluble microbial products & 56 \\
\hline WHoA & $320 / 395$ & humic-acid like products & 42 & $320 / 380$ & humic-acid like products & 36 \\
\hline \multirow[t]{2}{*}{ HiM } & $345 / 390$ & humic-acid like products & 32 & $390 / 390$ & humic-acid like products & 31 \\
\hline & & & & $298 / 280$ & Soluble microbial products & 79 \\
\hline
\end{tabular}

\section{CONCLUSIONS}

Ozonation alters the structures of DOM in petrochemical ROC to be more hydrophilic. Using RAC technique, ROC before and after ozonation is isolated into five fractions: HoA, HoB, HoN, WHoA, and HiM. Hydrophobic organics dominate in raw ROC, in which HoN and HoA account for $29.2 \%$ and $19.5 \%$, respectively. Ozone significantly decreases the percentage of $\mathrm{HoN}$, while increases the concentration of WHoA and HiM, resulting in relatively high hydrophilicity of ROC.

Ozonation decreases the molecular weight of raw ROC. The unsaturated groups and aliphatic structurs are destroyed greatly and converted to more C-O structures, which shows relatively high hydrophilicity and low molecular weight. Through the analysis of fluorescence spectroscopy, it is found that ozone decreases significantly the fluorescence intensity of humic-like and fulvic-like substances in DOM, whereas increaes the fluorescence intensity of soluble microbial products. The production of soluble microbial products cause ROC to be more hydrophilic, which contains more O-alky v(C-O) groups.

\section{CORRESPONDING AUTHOR}

Zhang Hua, zhanghua7977@163.com, 13401139727

\section{REFERENCES}

[1] Bagastyo A.Y., Keller J., Poussade Y. and Batstone D.J. Characterisation and removal of recalcitrants in reverse osmosis concentrates from water reclamation plants. Water Research, 2011, 45 (7): 2415-2427.

[2] Andreozzi R., Canterino M., Marotta R. and Paxeus N. Antibiotic removal from wastewaters: the ozonation of amoxicillin. Journal of hazardous materials, 2005, 122 (3): 243-250.

[3] Huber M.M., Canonica S., Park G.Y., and von Gunten U. Oxidation of pharmaceuticals during ozonation and advanced oxidation processes. Environmental Science and Technology, 2003, 37 (5): 1016-1024.

[4] Huber M.M., Gobel A., Joss A., Hermann N., Loffler D., McArdell C.S., Ried A., Siegrist H., Ternes T.A. and von Gunten U. Oxidation of pharmaceuticals during ozonation of municipal wastewater effluents: a pilot study. Environmental Science and Technology, 2005, 39 (11): 4290-4299.

[5] Ikehata K., Naghashkar N.J. and Ei-Din M.G. Degradation of aqueous pharmaceuticals by ozonation and advanced oxidation processes: a review. Ozone-Science \& Engineering, 2006, 28 (6): 353-414.

[6] Zhang H., Qu J.H., Liu H.J. and Zhao X. Isolation of dissolved organic matter in effluents from sewage treatment plant and evaluation of the influences on its DBPs formation. Separation and Purification Technology, 2008, 64 (1): 31-37.

[7] Leenheer J.A., Rostas C., and Barber L. Nature and chlorine reactivity of organic constituents from reclaimed water in groundwater, Los Angeles county, California. Environmental Science and Technology, 2001, 35 (19): 3869-3876.

[8] Imai A., Fukushima T. and Matsushige K. Characterization of dissolved organic matter in effluents from wastewater treatment plants. Water Research, 2002, 36 (4): 859-870.

[9] Leenheer J.A. Comprehensive approach to preparative isolation and fractionation of dissolved organic carbon from natural waters and wastewaters. Environmental Science and Technology, 1981, 15 (5): 
$578-587$.

[10] Chefetz B., Hatcher P.G. and Hadar Y. Characterization of dissolved organic matter extracted from composted municipal solid waste. Soil Science Society of America Journal, 1998, 62 (2): 326-332.

[11] Bruchet A., Anselme C., Duguet J.P. and Mallevialle J. THM formation potential and organic content: a new approach in water chlorination chemistry. Environmental Impact and Health Effects, 1987, 6: 633-647.

[12] Zhang H., Qu J.H., Liu H.J. and Zhao X. Characterization of isolated fractions of dissolved organic matter from sewage treatment plant and the related DBPs formation potential. Journal of hazardous materials, 2009, 164(2-3): 1433-1488.

[13] Schnitzer M. and Khan S.U. In Humic Substances in the Environment. Marcek Dekker: New York. 1972, 68-82.
[14] Aiken G.R., McKnight D.M., Wershaw R.L. and MacCarthy P. Humic Substances in Soils, Sediments and Water. John Wiley \& Sons: New York, 1985.

[15] Kanokkantapong V., Marhaba T.F. and Pavasant P. Characterization of haloacetic acid precursors in source water. Journal of environmental management, 2006, 80 (3): 214-221.

[16] Kim H.C. and Yu M.J. Characterization of natural organic matter in conventional water treatment processes for selection of treatment processes focused on DBPs control, Water Research, 2005, 39 (19): 4779-4789.

[17] Chen J., Gu B., Le Boeuf E.J., Pan H. and Dai S. Spectroscopic characterization of the structural and functional properties of natural organic matter fractions. Chemosphere, 2002, 48(1): 59-68. 